\title{
Endoscopic submucosal dissection with triangulated traction with clip and rubber band: the "wallet" strategy
}

Endoscopic submucosal dissection (ESD) is the reference method for the curative endoscopic resection of colorectal tumors [1, 2]. Nevertheless, it is technically challenging, and new strategies to facilitate the procedure are requested. Counter-traction strategies, such as the clip and rubber band approaches, allow the enlargement of the submucosal space $[3,4]$. In the colon, line traction makes a tangential traction without triangulation, and is not really adaptive as the dissection progresses [5]. We report a case of ESD for a colonic laterally spreading tumor in a patient with a history of pancolonic ulcerative colitis.

For this resection, we used the "wallet strategy" ( $\triangleright$ Video $\mathbf{1}$ ) in order to obtain a strong counter-traction to achieve en bloc resection in this fibrotic situation of ulcerative colitis. First, the two edges (oral and anal) of the lesion were incised. Then, trimming was performed at both edges in direct and retroflexed approaches, in order to achieve deep access to the submucosa and to release both mucosal edges ( $\mathbf{F i g} \mathbf{1}$ ).

After this step, two elastic rubber bands were fixed with hemoclips to both proximal and distal mucosal flaps. By trapping both rubber bands with a third metallic clip, we used triangulation traction and fixed the clip to the opposite mucosal wall (wallet aspect) (ฉ Fig.2). The submucosa was fibrotic and fatty, which is typical in ulcerative colitis. Thanks to this double traction, the submucosa was strongly stretched perpendicularly to the muscular layer plan ( Fig.3 d, > Fig.4), facilitating dissection.

This strategy must be compared prospectively with other traction strategies, but seems to offer a strong counter-traction with a perpendicular angle with the muscular layer. Stretching both proximal and distal edges allows the removal of the muscle from the cutting line and could improve safety. Furthermore, this strategy is adaptive, as the strength of

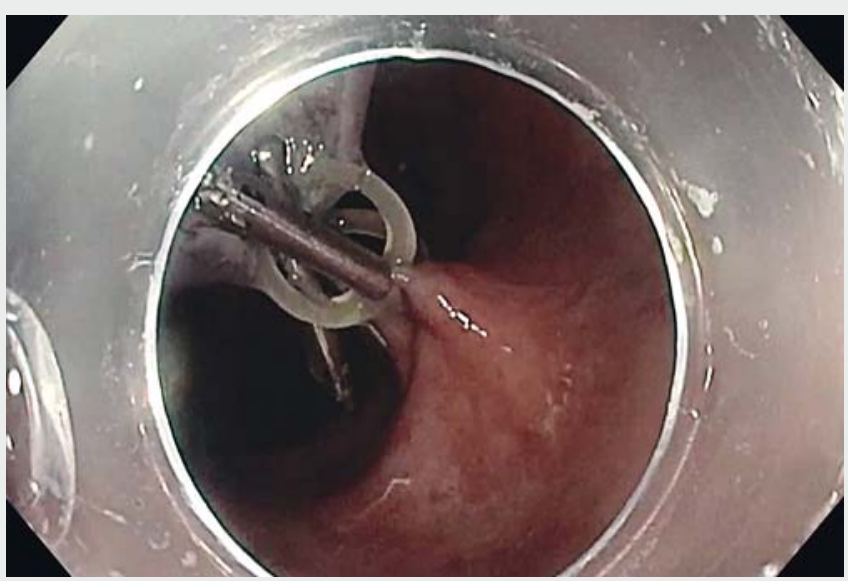

Video 1 Colorectal endoscopic submucosal dissection with the "wallet" traction strategy.

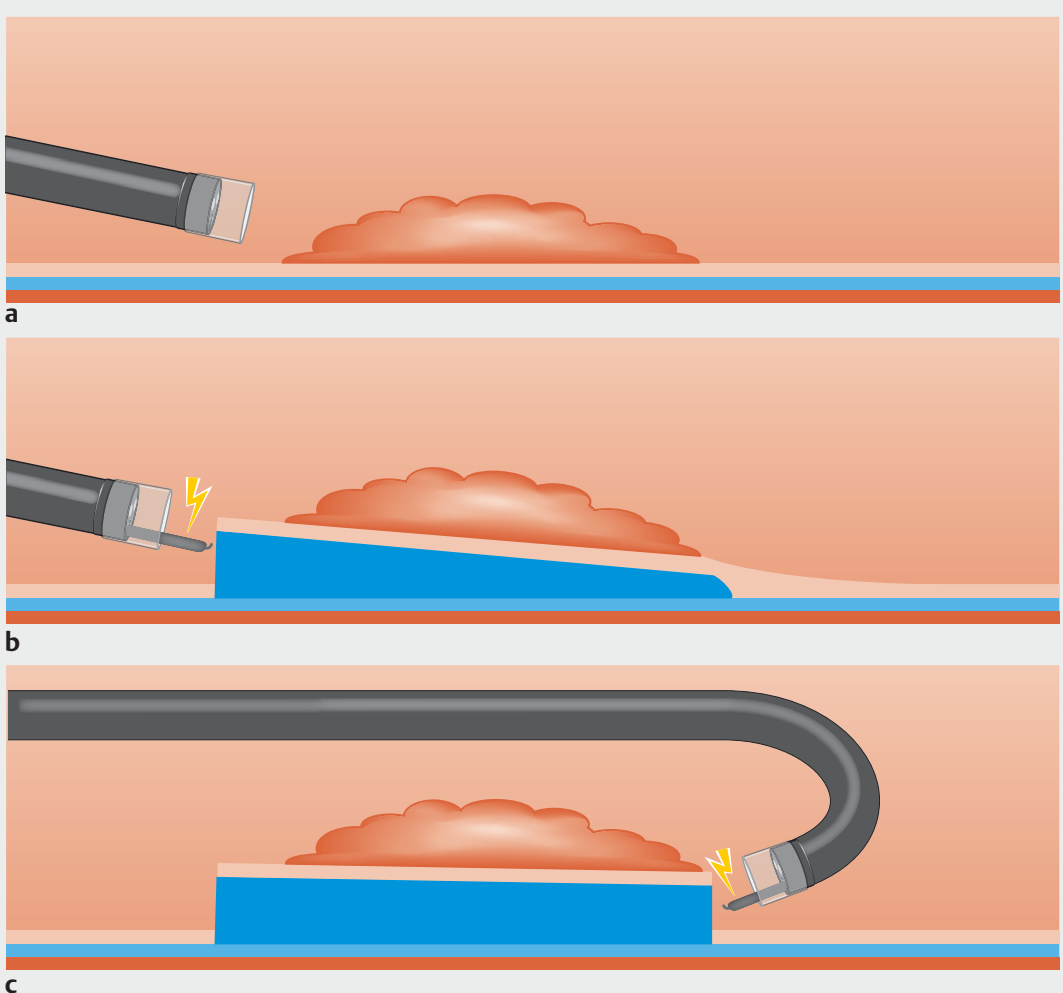

- Fig. 1 Schematic procedure for initial dissection. a Granular laterally spreading tumor. b Incision of anal side. $\mathbf{c}$ Incision of oral side in retroflexed position. 


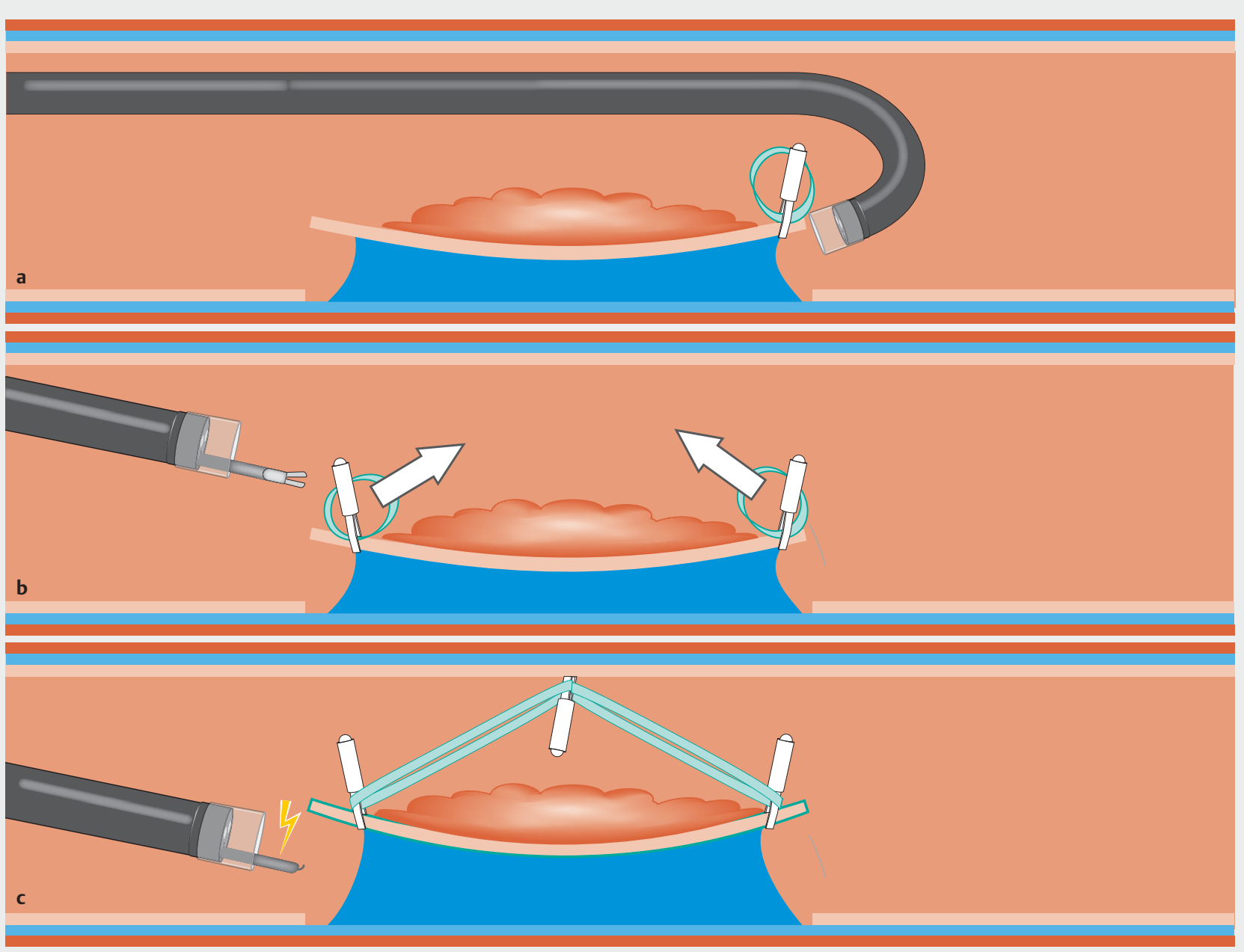

- Fig. 2 Schematic for traction part of the procedure. a Placement of first clip and rubber band. $\mathbf{b}$ Placement of second clip and rubber band. c Triangulation obtained by fixing both clips to the opposite mucosal wall, and dissection of the residual stretched submucosal.

the rubber band traction changes with insufflation and with dissection progression ( Fig. 2c).

\section{Endoscopy_UCTN_Code_TTT_1AQ_2AZ}

\section{Competing interests}

None
The authors

Alexandru Lupu ${ }^{1,2}$, Jérémie Jacques ${ }^{3}$, Jérôme Rivory', Florian Rostain ${ }^{1}$, Frédéric Pontette ${ }^{4}$, Thierry Ponchon', Mathieu Pioche ${ }^{1,5}$

1 Gastroenterology and Endoscopy Unit, Pavillon H, Edouard Herriot Hospital, Lyon, France

2 Gastroenterology Department, Fundeni Hospital, Bucharest, Romania

3 Gastroenterology and Endoscopy Unit, Dupuytren University Hospital, Li-moges, France

4 Polyclinique Lyon Nord, Rillieux-la-pape, France

5 Inserm U1032, Labtau, Lyon, France

\section{Corresponding author}

\section{Alexandru Lupu, MD}

Endoscopy Unit, Digestive Disease Department, H Pavillon, Edouard Herriot Hospital, 69437 Lyon Cedex, France Fax: +33-4-72110147

alexandru.lupu@chu-lyon.fr 

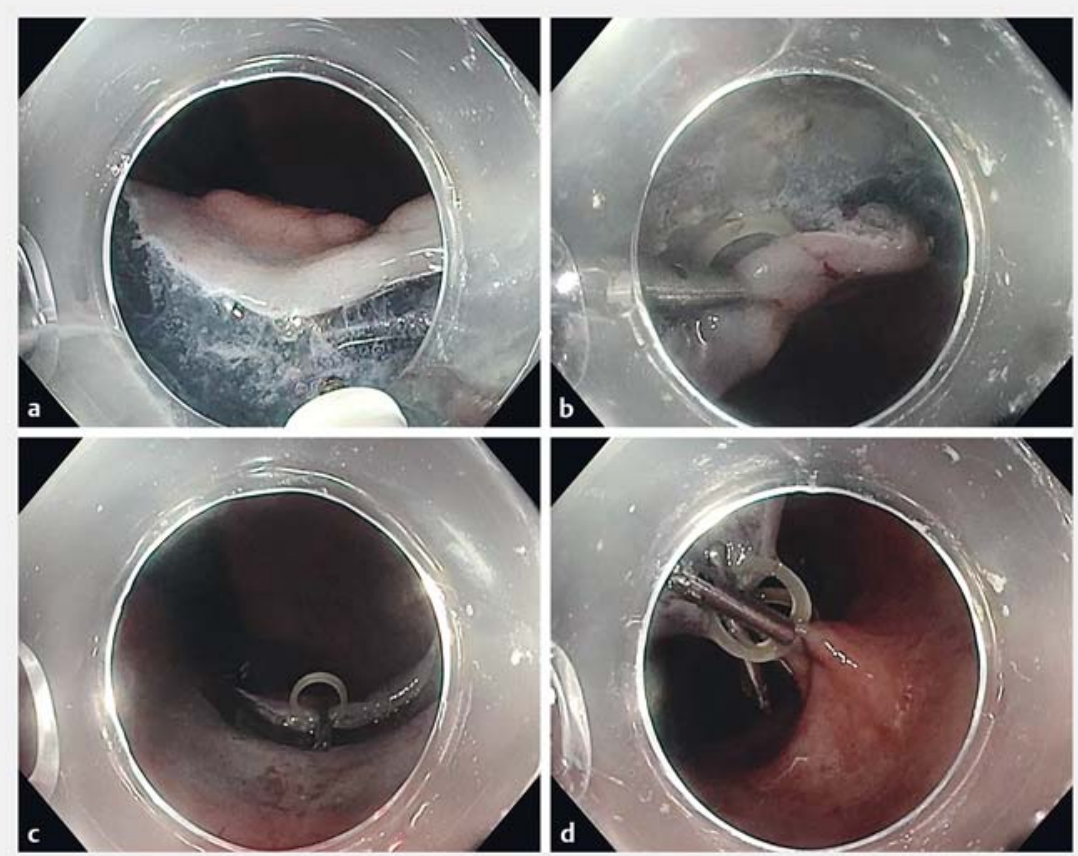

- Fig. 3 Endoscopic aspect. a Mucosal incision. b Distal clip rubber band placement. c Proximal clip rubber band placement in retroflexion. $\mathbf{d}$ Fibrotic submucosa stretched as a result of the traction.
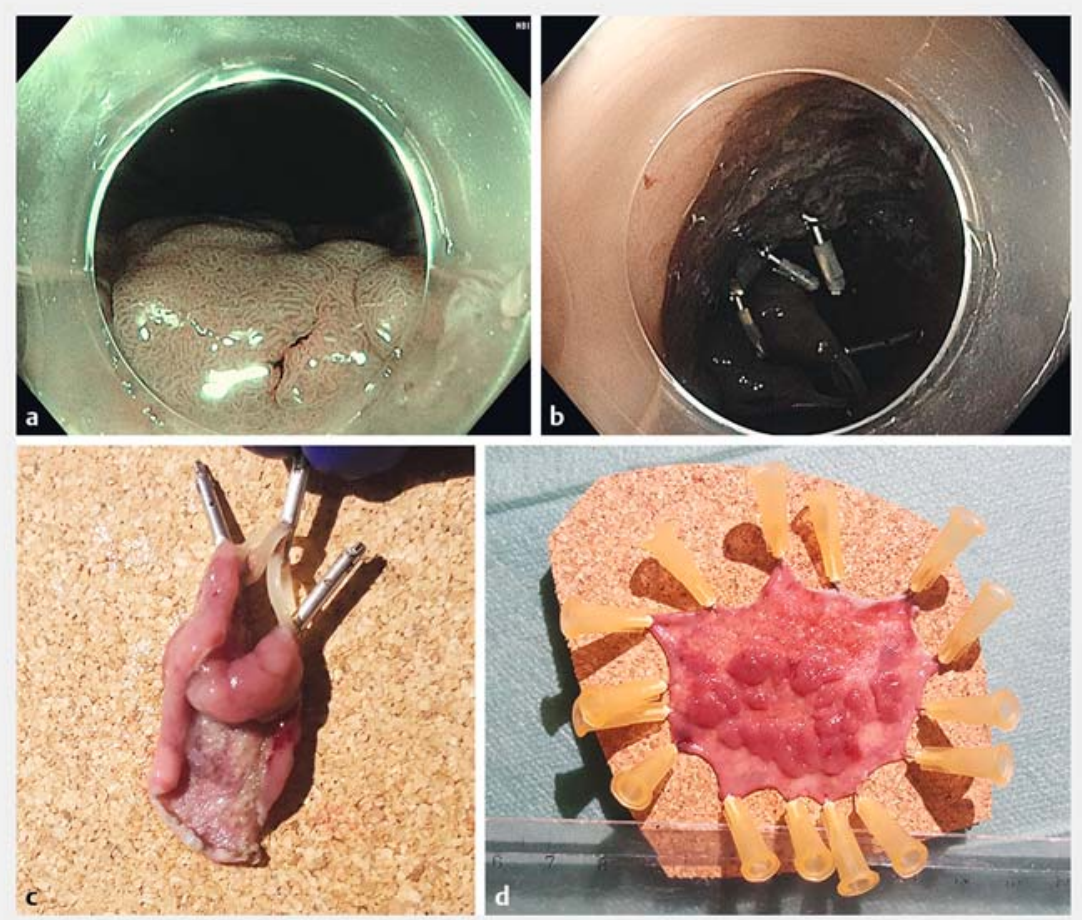

- Fig. 4 Colonic laterally spreading tumor. a Narrow-band imaging characterization. b End of dissection, closing the mucosal defect with clips. c Specimen after removal. d Stretched specimen with scar on cork.

\section{References}

[1] Saito Y, Uraoka T, Yamaguchi Y et al. A prospective, multicenter study of 1111 colorectal endoscopic submucosal dissections (with video). Gastrointest Endosc 2010; 72 : $1217-1225$

[2] Pimentel-Nunes P, Dinis-Ribeiro M, Ponchon $T$ et al. Endoscopic submucosal dissection: European Society of Gastrointestinal Endoscopy (ESGE) Guideline. Endoscopy 2015; 47: $829-854$

[3] Utzeri E, Jacques ], Charissoux A et al. Traction strategy with clips and rubber band allows complete en bloc endoscopic submucosal dissection of laterally spreading tumors invading the appendix. Endoscopy 2017; 49: 820-822

[4] Jacques ], Charissoux A, Legros R et al. Double-clip counter-traction using a rubber band is a useful and adaptive tool for colonic endoscopic submucosal dissection. Endoscopy 2018; 50: 179-181

[5] Jacques J, Legros R, Rivory J et al. The "tunnel + clip" strategy standardised and facilitates oesophageal ESD procedures: a prospective, consecutive bi-centric study. Surg Endosc 2017; 31: $4838-4847$

\section{Bibliography}

DOI https://doi.org/10.1055/a-0624-1721

Published online: 28.6.2018

Endoscopy 2018; 50: E256-E258

(c) Georg Thieme Verlag KG

Stuttgart · New York

ISSN 0013-726X

\section{ENDOSCOPY E-VIDEOS}

https://eref.thieme.de/e-videos

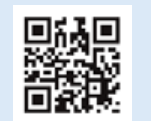

Endoscopy E-Videos is a free access online section, reporting on interesting cases and new techniques in gastroenterological endoscopy. All papers include a high quality video and all contributions are freely accessible online.

This section has its own submission website at

https://mc.manuscriptcentral.com/e-videos 